\title{
Situation and Countermeasures of SMEs Under Pneumonia Epidemic COVID-19
}

\author{
Fangzhe Liao, Kun Xiong, Qian Gao, Jinrui Zeng
}

\author{
School of Business, Jiangxi Normal University, Nanchang 330022, China \\ *Corresponding author. Email:2958310147@qq.com
}

\begin{abstract}
With the rapid development of China's economy, SMEs have played an increasingly important role in China's economic development. However, the outbreak and spread of COVID-19 had a great impact on economic development, especially on the development of SMEs. In this context, the development problems of SMEs in China have gradually become prominent. Based on the basic situation of the development of SMEs presently in China, this paper analyzes the difficulties and opportunities faced by SMEs under the epidemic situation. Through the analysis of the current situation of typical enterprises, it presents the new face of SMEs after taking measures against the epidemic situation, and to the measures to choose the correct path to turn crisis into safety. The purpose of this paper is to analyze the impact of pneumonia epidemic in COVID-19 on SMEs and put forward some relevant measures and suggestions.
\end{abstract}

Keywords: SMEs, COVID-19 epidemic, condition, countermeasure and suggestion

\section{INTRODUCTION}

At the beginning of the 2020 New Year, just as we stopped busy to enjoy family reunion, a sudden pneumonia epidemic in COVID-19 caught us off guard. General Secretary Xi Jinping emphasized: "Continue to study and introduce phased and targeted tax reduction and fee reduction policies to help SMEs tide over the difficulties." The impact of pneumonia epidemic on economic operation in COVID-19 is mainly reflected in aggravating the difficulties in production and operation of industrial enterprises, especially small and medium-sized enterprises, delaying the progress of investment projects and increasing the pressure to stabilize employment. Faced with the epidemic, SMEs face severe challenges because of their small scale, weak strength and low ability to resist risks, especially in retail and wholesale, transportation, accommodation and catering, film and entertainment, cultural tourism, construction, laborintensive manufacturing and other industries, which have a great impact on them [1]. How to get rid of difficulties for SMEs is the top priority of current economic work.

\section{A SURVEY OF SMES UNDER THE PNEUMONIA EPIDEMIC COVID-19}

With the improvement of national economic strength, the rapid development of SMEs plays an important role in economic development. According to the statistics of the Ministry of Industry and Information Technology, by the end of 2018, the number of SMEs in China has exceeded 30 million, accounting for more than $90 \%$ of the total number of enterprises, and SMEs have become the main component of the current Chinese enterprise market. At the end of 2018, the income from the main business of SMEs in China was 57.9 trillion yuan, an increase of $8.4 \%$ compared with the previous period. In terms of regulations, the proportion of the main business income of enterprises was $56.7 \%$, which was 0.1 percentage points lower than the growth rate of enterprises in the same period $(8.5 \%)$; Among them, the main business income realized by medium-sized enterprises was 23.3 trillion yuan, an increase of $8.7 \%$. In addition, SMEs provide more employment opportunities, which alleviate the employment pressure of society to a certain extent. Moreover, SMEs can flexibly adapt to the market and give full play to the innovative spirit of employees [2].

Due to capital, technology, management and other factors, the anti-risk ability of SMEs is generally weaker than that of large enterprises. The outbreak of pneumonia in COVID-19 has brought great pressure to the majority of small and medium-sized enterprises, including operating pressure, financial pressure and even survival pressure. On April 17, the National Bureau of Statistics announced the gross domestic product (GDP) in the first quarter of 2020. According to preliminary calculation, the GDP in the first quarter was $20,650.4$ billion yuan, which was $6.8 \%$ lower than the same period of last year at comparable prices. In terms of industries, the added value of the primary industry was $1,018.6$ billion yuan, down $3.2 \%$; The added value of the secondary industry was 7,368.3 billion yuan, down $9.6 \%$; The added value of the tertiary industry was 12.268 trillion yuan, down $5.2 \%$. The data show that the pneumonia epidemic in COVID-19 has inevitably caused a great impact on China's economy and society [3-4]. 


\section{THE IMPACT OF PNEUMONIA EPIDEMIC COVID-19 ON SMES}

\subsection{Lower Consumer Demand, Reduced Orders}

The spread of the COVID-19 epidemic is a long process, which also has a negative impact on the production and development of SMEs. Under the strong leadership of the CPC Central Committee, all provinces and cities coordinate and act urgently, and fight hard. All regions in the country insist on seeking truth from facts, listen to the arrangement of superiors, and take measures of regional isolation, which to a great extent limits the flow of population between regions. The spread of the epidemic also leads to the huge defeat of the purchasing desire and consumption enthusiasm of the vast number of consumer groups.

At the same time, the continuous strengthening of the control measures to stop production and production also makes the upstream manufacturers who provide raw materials unable to carry out production. At the same time, the strict control of traffic roads also causes the timely supply of materials and products, and many SMEs are basically unable to carry out orderly production and operation; Each of the above-mentioned restrictions will cause a rapid decline in the demand for orders from SME customers, and even fail to receive any orders for a long time, which will threaten the normal operation of enterprises, especially for the garment industry that needs a large number of orders and needs convenient transportation [5]; On the other hand, due to the global spread of COVID-19 epidemic, foreign consumers' desire for Chinese products will also be impacted.

Meanwhile, foreign companies cooperating with domestic SMEs will correspondingly reduce the number of orders and even give up the Chinese market. On the contrary, they will seek opportunities for similar enterprises to cooperate from their own countries, which will inevitably lead to a sharp drop in orders of Chinese SMEs in the international market. In addition, due to the impact of the epidemic, aviation and navigation traffic at home and abroad are seriously blocked. Orders at home and abroad can't be purchased and delivered smoothly, and consumers' demands can't be met, which may lead to the shift of flow direction and even the loss of market orders. Moreover, if the COVID-19 epidemic is well controlled, the recovery period of SMEs will be unpredictable and hierarchical. At present, it is still in the suspension stage, and the recovery speed in the future can be expected to be slow.

\subsection{The Risk of Capital Chain Breakage Has Increased, and the Problem of Financing Difficulties Has Intensified}

Due to the spread of COVID-19 epidemic, SMEs are in an awkward middle area, and upstream raw material suppliers are unable to carry out good production due to strict shutdown measures. At the same time, the unsmooth transportation also makes the supply channels of raw materials unable to circulate with high quality; However, the orders for long-term cooperation will gradually and rapidly decrease, which will affect the stability of cooperation, and the benefits of enterprises will decrease instead of increase.

In the face of rapidly decreasing orders, the main crisis faced by SMEs at the moment is the lack of funds, and the company's production efficiency cannot be guaranteed. At the same time, employees' wages, factory rents, office rents and other expenses generated during the epidemic shutdown cannot be guaranteed, but these expenses are precisely the majority of the production costs of enterprises. The increasing risks of enterprises will easily lead to the interruption of cash flow and the risk of capital chain breakage. Before the outbreak, the financing dilemma of SMEs was a topic of social concern.

SMEs have weak ability to resist risks, and banks are more willing to choose large and medium-sized enterprises as loan objects from the perspective of loan security. The low credit rating of SMEs also affects the enthusiasm of bank loans and causes great damage to the maintenance of enterprise capital chain.

\subsection{The Ability to Resist Risks is Insufficient}

SMEs have small scale of operation, weak ability to resist risks, fierce competition in the industry and great difficulty in survival. Because the credit level of most SMEs is low, after the epidemic, in order to alleviate the financial pressure, SMEs will face many restrictions in raising funds from banks and other financial institutions, resulting in a shortage of funds when SMEs are in urgent need of capital turnover. In addition, most investors in SMEs are decision makers. Some decision makers have no professional management training, lack relevant professional qualities, and often make wrong financial management decisions. In the face of emergencies, they cannot make timely decisions that are conducive to enterprises to break through in the fight against pneumonia in COVID-19 [6-7]. In a word, both the shortage of funds and managers' lack of experience in decision-making and management make enterprises lack the ability to resist risks, that is, SMEs lack the ability to fight against COVID-19 pneumonia and break through successfully. 


\section{TAKE NT COMPANY AS AN EXAMPLE}

NT Company, located in Wuhan, Hubei Province, was registered and established in February 2007 in the local market supervision administration with a registered capital of 500,000 yuan. The company is mainly engaged in the processing and sales of egg products. Since its establishment, the company has always been aiming at providing high-quality and healthy egg products for the society and serving as a bridge between farmers and citizens. The products have been well received by customers and consumers.

\subsection{The Impact on Business Income}

NT Company is mainly engaged in the processing and sales of egg products. Its main sales channels are supermarkets, e-commerce and export trade. Its customer groups include citizens, restaurants and food factories. Under the pneumonia epidemic in COVID-19, it was implemented all over China.

Strict traffic control measures and epidemic prevention and control measures have greatly affected NT's product sales. Many catering and food manufacturers have cancelled orders, and logistics suspension has led to the stagnation of e-commerce sales. This makes the company's sales face unprecedented pressure, and its operating income has dropped significantly compared with the same period in 2019. In February, 2019, due to the peak season of egg products sales around Spring Festival, the company's operating income reached 4.45 million yuan, with large customer demand and considerable product profits. In February, 2020, the company's operating income was 330,000 yuan, and the income decreased by more than $90 \%$, mainly because local governments introduced traffic control measures during the epidemic, and factories, upstream suppliers and restaurants closed down, which affected the sales of products.

\subsection{The Impact on Enterprise Capital Turnover}

Enterprises need a certain amount of liquidity to meet their own production and operation needs. NT Company mainly sells agricultural products, and the recovery of product funds needs a certain period, which requires the company to have a certain amount of liquidity. In February 2019, NT's working capital can maintain the turnover of the company for 4 months. Due to the influence of pneumonia epidemic in COVID-19, the current working capital of NT Company can only maintain a turnover of 2 months. This is mainly caused by two reasons: on the one hand, the foreign sales of products are greatly affected, and the overall capital inflow of the company is reduced, which inevitably increases the financial pressure of the company; On the other hand, during the epidemic, people's demand for going out to shop was greatly reduced, which extended the cycle of capital recovery to a certain extent and increased the pressure of capital turnover.

\subsection{Influence on the Pressure of Payment Cost}

NT Company is facing great payment pressure in the development process, which mainly comes from employees' wages and social security, rent, repayment of loans, payment of accounts payable and so on. Under the influence of pneumonia epidemic in COVID-19, NT's operating income declined greatly, and its liquidity decreased greatly compared with the same period in 2019 . However, the fixed costs such as employees' wages and rents did not change, which virtually increased the cost payment pressure of enterprises. Through the survey, it was found that the payment pressure of employees' wages and five insurances and one gold increased by $52.12 \%$ compared with the same period of 2019; The payment pressure of rent increased by $23.63 \%$ compared with the same period of 2019; The pressure to repay loans has increased by $22.56 \%$ compared with the same period in 2019; The pressure to pay accounts payable increased by $31.89 \%$ compared with the same period in 2019 . It can be seen that due to the influence of pneumonia in COVID-19, the payment cost of NT Company has greatly increased, which virtually increases the survival pressure of the company, and makes the pressure of the company suddenly increase in the process of facing fierce external competition, thus affecting the long-term development of the company.

\section{COUNTERMEASURES FOR SMES}

\subsection{Alleviate the Long-standing Financing Problems}

Financing difficulty is a major problem faced by SMEs in China. According to the report "Entrepreneur and SME Financing" published by the Organization for Economic Cooperation and Development (OECD) in 2019, only $53.1 \%$ of SMEs applying for loans from banks in China received loan funds in 2017, and this proportion also decreased by $16.8 \%$ and $10.0 \%$ respectively compared with 2015 and 2016 .

At present, the source of funds for SMEs in China is mostly bank loan funds, but the small market scale of SMEs' production and operation and the great risks they face make it difficult to obtain bank loan. Most of the banks that lend money to SMEs are policy banks and small and medium-sized city commercial banks.

Faced with this situation, to solve this long-standing problem, we need to work from the following two aspects: firstly, the state should support the establishment of more 
policy banks, support the development of small and medium-sized enterprises, and provide more relaxed and convenient conditions for financing of small and mediumsized enterprises. Secondly, we should also set a lending ratio for major state-owned commercial banks, and require major state-owned commercial banks to lend to SMEs in a prescribed proportion to "hematopoietic" for small and medium-sized enterprises; Thirdly, the incentive mechanism should be established, so that small and medium-sized city commercial banks and rural commercial banks that lend a large amount of money to SMEs can enjoy certain preferential tax rates, so as to continue to support city commercial banks and rural commercial banks in lending to small and medium-sized enterprises. Fourthly, the development of SMEs should be included in the assessment system as a reference element for local officials' achievements. On the other hand, SMEs should actively obtain relevant information, strive to seize preferential policies, actively seek more financing channels, and seize opportunities for their own development.

\subsection{SMEs are Moving Towards Transformation and Upgrading}

At present, China's SMEs are mostly in a disadvantaged position in the market competition, lacking talents, backward technology, low added value, lack of core competitive advantage, and the mode of operation is solidified, lacking innovative thinking. Under the impact of the COVID-19 epidemic, many SMEs are in a difficult situation because of their difficulty in starting work and lack of market. However, some SMEs have innovated their business models in time. For example, the catering industry has cooperated with Meituan and Hungry, and has weathered the difficulties and even ushered in opportunities for development, creating higher profits and winning better development; There is also the vegetable and fruit industry, which has cooperated with JD.COM to bring fruits and vegetables to the door, and has also achieved a large market and rapid development. All these inspire us that SMEs should be good at seeking opportunities, constantly improving themselves and adapting to consumers' consumption habits and thinking. When the epidemic situation is getting better, SMEs should be good at changing their business models, dare to innovate, and insist on running online and offline at the same time, so as to successfully get rid of the difficult situation for enterprises. Forced by the epidemic, it is the only way for SMEs to change their business models and realize transformation and upgrading.

\subsection{Reduce the Burden on SMEs}

At present, small and medium-sized enterprises, in addition to the bank's high interest rate lending costs, also have various taxes and fees that have brought many economic costs and increased many invisible economic pressures. Therefore, tax reduction and fee reduction are important measures to help SMEs survive the severe winter. SMEs are small in scale and weak in anti-risk, especially in the face of such global systemic risks, and they are even more precarious and unable to bear the pressure of various taxes and fees. Therefore, during the epidemic, the government reduced the tax rate and canceled some unreasonable and unfair charges, which is undoubtedly a timely help for small and medium-sized enterprises. To "relax" SMEs, it is imperative to reduce taxes and fees.

\section{SUMMARY}

After the outbreak of pneumonia COVID-19, it has brought obvious pressure to the development of SMEs in China, which seems to be a disaster, but in fact it is a turning point. Through analysis, it is found that the main factors that inhibit the development of SMEs in COVID19 pneumonia epidemic are the capital chain and financing difficulties that SMEs should solve. Traditional SMEs should deeply realize the importance of transformation and upgrading through this epidemic crisis, quickly adapt to the economic development needs of the new information technology era, adapt to the huge changes in mass consumption habits and lifestyles, and achieve leap-forward development in the crisis.

\section{REFERENCES}

[1] Hou Qin, Wang Jiaojiao. Analysis on the Breakthrough Path of SMEs under the Epidemic Situation [J]. Hebei Enterprise, 2020(05):97-98.

[2] Foshan Daily reporter Ye Xiaoqing. SMEs should focus on improving their ability to resist risks [N]. Foshan Daily, 2020-04-13(A05).

[3] Meng Shuyan, Dong Zuofeng, Meng Ruiquan. A summary of the research on the development of SMEsbased on the background of regional coordinated development $[\mathrm{J}]$. Modern Marketing (Information Edition), 2020(02):123.

[4] Rollin Wang. Crisis and coping strategies of private SMEsunder pneumonia epidemic in COVID-19 [J]. Journal of Sichuan Institute of Socialism, 2020(01):48-54.

[5] Xu Yude. The challenges faced by SMEsunder the impact of the global epidemic and their 
countermeasures $[\mathrm{J} / \mathrm{OL}]$. monthly accounting journal: 1-5 [2020-06-05].

http://kns.cnki.net/kcms/detail/42.1290.f.20200529.529

0000005

[6] Zhang Jingwei, a visiting researcher at Chongyang Institute of Finance, Renmin University of China, made a good fight for the survival of SMEs under the "war epidemic" of the whole people [N]. national business daily, 2020-02-19(007).

[7] Cai Yaxuan. Study on the Influence of Pneumonia Epidemic in COVID-19 on SMEsand Countermeasures Taking NT Company as an example [J]. Financial Management Research, 2020(04):59-64. 